\title{
Controllable synthesis, characterization and photocatalytic studies on cadmium
} vanadate nanostructures

\author{
Fatemeh Mazloom ${ }^{\text {a }}$, Maryam Masjedi-Arani ${ }^{\text {b }}$, Masoud Salavati-Niasari ${ }^{* a}$ \\ Institute of Nano Science and Nano Technology, University of Kashan, Kashan, P.O. Box 87317-51167, I. R. \\ Iran \\ ${ }^{b}$ Young Researchers and Elite Club, Arak Branch, Islamic Azad University, Arak, Iran. \\ *Corresponding author: Tel.: +98 315591 2383, Fax: +98 3155913201; Salavati@kashanu.ac.ir
}

\begin{abstract}
Cadmium vanadate $\left(\mathrm{Cd}_{2} \mathrm{~V}_{2} \mathrm{O}_{7}\right)$ nanocrystals have been successfully synthesized via simple coprecipitation method by using $\mathrm{Cd}\left(\mathrm{NO}_{3}\right)_{2} \cdot 4 \mathrm{H}_{2} \mathrm{O}$ and $\mathrm{NH}_{4} \mathrm{VO}_{3}$ as starting materials. Effects of various amines, temperature, reaction time, solvent, $\mathrm{pH}$ were investigated to reach optimum condition. It was found that particle size, morphology and phase of the as-prepared products could be greatly influenced via these parameters. The products were characterized by X-ray diffraction (XRD), Fourier transform infrared (FT-IR) spectra, energy dispersive X-ray microanalysis (EDX), scanning electron microscopy (SEM) and transmission electron microscopy (TEM). The photocatalytic activity of cadmium vanadate nanostructures was investigated by degradation of anionic dye of eosin $\mathrm{Y}$ in aqueous solution under visible light irradiation.
\end{abstract}

Keywords: $\mathrm{Cd}_{2} \mathrm{~V}_{2} \mathrm{O}_{7}$; Nanostructures; Optical properties; Photocatalytic activity; Electron microscopy.

\section{Introduction}

In recent years, metal vanadates have attracted signicant interest, due to their extensive technological importance in a wide range of applications, including catalysis [1], cathode materials in batteries [2], implantable cardiac defibrillators (ICDs) [3] and low-temperature magnetic devices [4]. Lots of research has 
22 been focused on the synthesis of metal vanadates of silver, copper, manganese, iron, bismuth and indium

23 from different approaches. In this paper, Cadmium vanadate was selected as an interesting material to its

24 excellent optical and chemical properties. Di li et al synthesized $\mathrm{CdV}_{2} \mathrm{O}_{6}$ and $\mathrm{Cd}_{2} \mathrm{~V}_{2} \mathrm{O}_{7}$ via hydrothermal

25 method and investigated photocatalytic activity of $\mathrm{CdV}_{2} \mathrm{O}_{6}$ and $\mathrm{Cd}_{2} \mathrm{~V}_{2} \mathrm{O}_{7}$ samples for the degradation of

26 methylene blue under visible-light irradiation [5]. Herein, we develop the precipitation method to synthesize

27 of cadmium vanadate nanocrystals. The precipitation method is a suitable synthesis process for prepare of

28 many nano products [6-8]. This method is simple, potential for large scale Production, convenient and cost

29 effective synthetic procedure and provides an effective way to the synthesis of uniform nanocrystals. In this

30 method, crystallization way is done at low temperature and design of reaction condition is very flexible. In

31 this paper, $\mathrm{Cd}_{2} \mathrm{~V}_{2} \mathrm{O}_{7}$ nanoparticles were synthesized by a precipitation method using novel basic agents to

32 adjust the $\mathrm{pH}$ value to 8-9. The purpose of this study is investigating the role of different amines on the size,

33 morphology and uniformity of the pure $\mathrm{Cd}_{2} \mathrm{~V}_{2} \mathrm{O}_{7}$ nanocrystals. The selected amines are chosen in a way that

34 we investigate the effect of different amines with different nitrogen active sites. The long carbon chain of

35 amines can provide great steric hindrance to control the size of nanoparticles.Recently our team has focused

36 on the effect of different amines as a basic and capping agent [9-11]. It has been demonstrated that these kind

37 of amines have an effective role on controlling size, shape, and optical properties of final products. The

38 effects of different parameters such as Effects of various amines, temperature, reaction time, solvent and $\mathrm{pH}$

39 on the product size, morphology and uniformity were also investigated. Moreover, the photocatalytic

40 degradation activity of anionic dye of eosin $\mathrm{Y}$ as water pollutant is performed to study the catalytic properties

41 of as-produced $\mathrm{Cd}_{2} \mathrm{~V}_{2} \mathrm{O}_{7}$ nanostructures.

\section{2. Experimental}

\subsection{Materials and Physical Measurements}


$\mathrm{Cd}\left(\mathrm{NO}_{3}\right)_{2} .4 \mathrm{H}_{2} \mathrm{O}, \quad \mathrm{NH}_{4} \mathrm{VO}_{3}, \quad \mathrm{NH}_{3}, \quad$ ethylenediamine (en), triethylenetetramine (TETA) and tetraethylenepentamine (TEPA) were purchased from Merck Company. All of the chemicals were used as received without further purifications. For characterization of the products, X-ray diffraction (XRD) patterns

47 were recorded by a Rigaku D-max C III, X-ray diffractometer using Ni-filtered Cu Ka radiation. Scanning 48 electron microscopy (SEM) images were obtained on Philips XL-30ESEM. Transmission electron 49 microscopy (TEM) image was obtained on a Philips EM208 transmission electron microscope with an 50 accelerating voltage of $200 \mathrm{kV}$. Fourier transform infrared (FT-IR) spectra were recorded on Shimadzu 51 Varian 4300 spectrophotometer in KBr pellets. GC-2550TG (Teif Gostar Faraz Company, Iran) were used 52 for all chemical analyses. Optical analyses were performed using a V-670 UV-Vis-NIR Spectrophotometer 53 (Jasco). Room temperature photoluminescence (PL) was studied on a Perkin Elmer (LS 55) fluorescence 54 spectrophotometer.

\subsection{Photocatalytic measurements}


The photocatalytic activity of cadmium vanadate nanoparticles was tested by using eosin Y solution. The degradation reaction was carried out in a quartz photocatalytic reactor. The photocatalytic degradation was carried out with $2 \times 10^{-5} \mathrm{M}$ of eosin Y solution containing $0.05 \mathrm{~g}$ of nanostructures. This mixture was aerated for $30 \mathrm{~min}$ to reach adsorption equilibrium. The experiments were performed at room temperature and $\mathrm{pH}$ of the eosin Y solution was adjusted 3. Aliquots of the mixture were taken at periodic intervals during the irradiation, and after centrifugation they were analyzed with the UV-Vis spectrometer. The dyes degradation

72 percentage was calculated as follows:

$73 \quad$ D.P. $(t)=\frac{\mathrm{A} 0-\mathrm{At}}{A 0} \times 100$

74 Where $A_{0}$ and $A_{t}$ are the absorbance value of solution at 0 and $t$ min, respectively.

\section{Results and discussion}

\subsection{X-ray diffraction patterns}

$\mathrm{XRD}$ analysis, which is the most useful technique for characterization of crystalline structure, was employed to investigate the purity of the prepared products. The X-ray diffraction patterns of as-prepared products obtained from the precipitation reaction are shown in Fig. 1. Fig. 1a-c show the XRD patterns of samples prepared at different $\mathrm{pH}$ (sample No. 1, 3 and 10), respectively. Fig. 1a shows the XRD patterns of samples prepared without adding of basic agent $(\mathrm{pH}=6)$. All the diffraction peaks are assigned to monoclinic- $-\mathrm{CdV}_{2} \mathrm{O}_{6}$ structure with space group of $\mathrm{C} 2 / \mathrm{m}$ and cell constants $\mathrm{a}=9.3590 \AA$, $\mathrm{b}=3.5680 \AA$, and $\mathrm{c}=6.9800 \AA$ (JCPDS Card No. 72-0546). With an increase of the pH ranges to 8-10 (Fig. 1b, c), most of the reflection peaks can be attributed to the monoclinic phase $\mathrm{Cd}_{2} \mathrm{~V}_{2} \mathrm{O}_{7}$ (JCPDS card No. 78-0951) and some weak diffraction evidence of residual $\mathrm{CdV}_{2} \mathrm{O}_{6}$ phase (JCPDS card No. 72-0546). It was found that the $\mathrm{CdV}_{2} \mathrm{O}_{6}$ and $\mathrm{Cd}_{2} \mathrm{~V}_{2} \mathrm{O}_{7}$ phases are stable in acidic and basic environment, respectively. the crystallite diameter $\left(D_{c}\right)$ of cadmium vanadate nanostructures obtained using the Scherrer equation $[12,13]: D=K \lambda / \beta \cos \theta$; where $\beta$ is the breadth of the observed diffraction line at its half intensity maximum, $\mathrm{K}$ is the so-called shape 
89 factor, which usually takes a value of about 0.9 , and $\lambda$ is the wavelength of X-ray source used in XRD.

90 Calculated crystalline domain sizes have been found to be 33, 27 and $29 \mathrm{~nm}$ for sample Nos. 1, 3 and 10,

91 respectively.

\section{3.2. SEM and TEM images}

93 To examine the role of the different basic agents on the morphology and size of the products, cadmium 94 vanadate nanostructures were synthesized by $\mathrm{NH}_{3}$, en, TETA and TEPA. SEM images of synthesized 95 product using different basic agents are illustrated in Fig. 2a-d, respectively. As shown in Fig. 2a-d, the 96 morphology of the samples cadmium vanadate synthesized by $\mathrm{NH}_{3}$, en, TETA and TEPA is spherical and 97 ellipsoids nanoparticles. Although morphologies of the products are the same, the size and uniformity of nanoparticles are different. The cadmium vanadate product synthesized by en amine is optimum product 99 because nanoparticles have smaller size and more uniformity. Schematic diagram of formation of cadmium vanadate products by different basic agent is depicted in Scheme. 1. The size and morphology of the products 101 were analyzed by the TEM image (Fig. 2e). Fig. 2e reveals that the cadmium vanadate nanoparticles (sample 102 No. 3) prepared with en basic and capping agent via precipitation method consisting sphere-like 103 nanoparticles with average particle size of 20 to $130 \mathrm{~nm}$. In order to investigate the effect of reaction time in 104 synthesis of cadmium vanadate products, the reaction is done at $20 \mathrm{~min}$ and $24 \mathrm{~h}$. Fig. $3 \mathrm{a}$, b show the effect 105 of time on the morphology and size of products. Optimum time for synthesis of fine and uniform cadmium 106 vanadate nanoparticles is $2 \mathrm{~h}$ (sample No. 3). Size of the microstructures produced after 20 min are not very 107 homogeneous. By increasing the reaction time to $24 \mathrm{~h}$, nanoparticles with larger size are achieved. Fig. 3c, d 108 show cadmium vanadate samples synthesized at different reaction temperatures of 3 and $80{ }^{\circ} \mathrm{C}$, respectively. 109 Room temperature is optimum temperature for synthesis of uniform nanostructures (Fig. 1b). Fig. 3e, f show the SEM images of samples prepared at $\mathrm{pH}$ of 6 and 10, respectively. Cadmium vanadate microstructures synthesized at acidic and basic environments ( $\mathrm{pH}=6$ and 10) are agglomerated. Therefore, concentration of 
$112 \mathrm{OH}^{-}$has an important role on size and morphology of prepared products. The effect of different solvents in

113 synthesis of cadmium vanadate structures were investigated. Fig. 4a-d show SEM images of cadmium

114 vanadate products prepared in presence of methanol, propyleneglycol, butanol and isobutanol, respectively.

115 As-prepared products in presence of all of them were agglomerated. Water solvent is suitable solvent for 116 synthesis of cadmium vanadate nanostructures (Fig. 2b).

\section{3.3. FT-IR and EDS spectra}

118 The surface conditioning of as-prepared cadmium vanadate nanoparticles was recorded using FT-IR 119 spectrum in order to detect the residual organic compounds. Fig. 5a shows FT-IR spectrum of sample No. 3. 120 The absorption bond centered at 3431 and $3252 \mathrm{~cm}^{-1}$ can be assigned to the stretching vibrations of the 121 hydrogen-bonded $\mathrm{OH}$ and $\mathrm{NH}$ groups, respectively. The vibration bonds at 876 and $668788 \mathrm{~cm}^{-1}$ are 122 attributed to tetrahedral $\mathrm{VO}_{4}$ vibration modes in the network. The absorption around $408 \mathrm{~cm}^{-1}$ correspond to 123 the stretching vibration $\mathrm{Cd}-\mathrm{O}$ band, which is consistent with octahedral $\mathrm{CdO}_{6}[14,15]$. The absorption peaks 124 at 1334 and $1577 \mathrm{~cm}^{-1}$ can ascribe to the overtone of $\mathrm{VO}_{4}$. Very weak peaks around $2937 \mathrm{~cm}^{-1} \mathrm{can}$ be 125 attributed to the asymmetric and symmetric stretching vibrations of aliphatic groups $\left(-\mathrm{CH}_{2}-\right)$ n, respectively 126 [16]. From the FT-IR result, it can be concluded that probably a small amount of ethylenediamine is attached 127 to the surface of cadmium vanadate nanoparticles which may have a well role in preventing nanoparticles 128 agglomeration. EDX further confirmed that the nanoparticles are composed of cadmium vanadate. The EDX 129 of the sample No. 3 is shown in Fig. 5b. Peaks associated with Cd, V and O are clearly observed and provide 130 strong evidence that the nanocrystals are composed of only $\mathrm{Cd}_{2} \mathrm{~V}_{2} \mathrm{O}_{7}$.

\section{3.4. Optical and photocatalytic properties}

132 The UV-Vis Diffuse Reflectance spectroscopy of sample No. 1 and 3 are shown in Fig 6a, b. As shown in

this figure the position of absorption edges are various. In comparison to the blank product without basic agent in acidic environment (sample No.1), the absorption edge of sample prepared with ethylenediamine 
135 shift to blue region. The fundamental absorption edge in most semiconductors follows the exponential law.

136 Using the absorption data, the band gap was estimated by Tauc's relationship:

$137 \alpha=\frac{\alpha_{0}\left(h v-E_{\mathrm{g}}\right)^{\mathrm{n}}}{\mathrm{hv}}$

138 where $\alpha$ is absorption coefficient, $\mathrm{h} v$ is the photon energy, $\alpha_{0}$ and $\mathrm{h}$ are the constants, $\mathrm{E}_{\mathrm{g}}$ is the optical band 139 gap of the material, and $n$ depends on the type of electronic transition and can be any value between $1 / 2$ and 3

140 [17]. The energy gaps of the samples have been determined by extrapolating the linear portion of the plots of $141(\alpha \mathrm{h} v)^{2}$ against $\mathrm{h} v$ to the energy axis (Fig. $6 \mathrm{c}$ and d). The $\mathrm{E}_{\mathrm{g}}$ values are calculated 3.2 and $3.3 \mathrm{eV}$ for the 142 samples No. 1 and 3, respectively. The difference of band gap values have been attributed to variations in the 143 impurities content, the crystalline size and the type of electronic transition [18, 19]. Optical properties of 144 cadmiun vanadate nanocrystals are of great importance as they provide information for the uses of these 145 materials in photocatalytic applications. The photocatalytic activity of cadmium vanadate nanoparticles 146 (sample No. 1,3) was investigated by monitoring the degradation of eosin $\mathrm{Y}$ as water pollutant in an aqueous 147 solution under visible light irradiation. The obtained results are shown in Fig. 7. According to photocatalytic 148 calculations by Eq. (1), the eosin Y degradation was about 57 (sample No. 1) and 47\% (sample No. 3) after 149200 min irradiation of visible light. By decreasing of particles size, energy gap and UV irradiation absorption 150 increased and as a result visible light absorption decreased. These results indicated that cadmium vanadate 151 nanocrystals are suitable photocatalyst under visible light in the short time.

\section{4. Conclusions}

153 We employed a facile precipitation method to synthesize cadmium vanadate nanostructures with aid of 154 different amines as a novel basic agent and size controller. The effect of different parameters such as reaction 155 time, temperature, $\mathrm{pH}$ and solvent on the size, morphology and uniformity of products were investigated. 156 Cadmium vanadate nanocrystals were characterized by XRD, SEM, TEM, EDS, FT-IR and DRS. Different 
157 morphology and size of products were prepared. The photocatalytic behavior of nanoparticles was evaluated 158 using the degradation of eosin Y aqueous solution under visible light irradiation.

159 Acknowledgments

160 Authors are grateful to the council of Iran National Science Foundation (91053846) and University of 161 Kashan for supporting this work by Grant No (159271/666). 


\section{References}

164 [1] M. Masato, M. Yui, M. Yuichi, I. Keita, Chem. Commun. 47 (2011) 9591-9593.

165 [2] L. Q. Mai, L. Xu, C. H. Han, X. Xu, Y. Z. Luo, S. Y. Zhao, Y. L. Zhao, Nano. Lett. 10 (2010) 47501664755.

167 [3] A. M. Crespi, S. K. Somdahl, C. L. Schmidt, P. M. Skarstad, J. Power Sources. 96 (2001) 33-38.

168 [4] G. Liu, J. E. Greedan, J. Solid. State. Chem. 114 (1995) 499-505.

169 [5] D. Li, X. Bai, C. Pan and Y. Zhu, Eur. J. Inorg. Chem. 2013 (2013) 3070-3075.

170 [6] Z. Shahri, A. Sobhani, M. Salavati-Niasari, Mater. Res. Bull. 48 (2013) 3901-3909.

171 [7] F. Beshkar, S. Zinatloo-Ajabshir, M Salavati-Niasari, Chem. Eng. J. 279 (2015) 605-614.

172 [8] G. Kianpour, M. Salavati-Niasari, Emadi H, Superlattice. Microst. 58 (2013) 120-129.

173 [9] F. Mazloom, M. Masjedi-Arani, M. Salavati-Niasari, J. Mater. Sci. 10.1007/s10854-015-3980-5 (2015) 11749.

175 [10] F. Mazloom, M. Masjedi-Arani, M. Ghiyasiyan-Arani, M. Salavati-Niasari, J. Mol. Liq. 214 (2016) $46-$ 17653.

177 [11] N. Mir, M. Salavati-Niasari, Electrochim. Acta. 102 (2013) 274-281.

178 [12] M. Masjedi-Arani, M. Salavati-Niasari, Ultrason. Sonochem. 29 (2016) 226-235.

179 [13] M. Masjedi-Arani, M. Salavati-Niasari, J. Mater. Sci. 26 (2015) 2316-2322.

180

[14] P. Huang, X. Zhang, J. Wei, J. Pan, Y. Sheng, B. Feng, Mater. Chem. Phys. 147 (2014) 996-1002. 
181 [15] R. Lozada-Morales, A. Cid-Garcia, G. López-Calzada, M. E. Zayas, O. Zelaya-Angel, J. Carmona182 Rodriguez, E. Rubio-Rosas, R. Palomino-Merino, O. Portillo-Moreno and S. Jiménez-Sandoval, Phys. 183 Status. Solidi. A. 209 (2012) 2281-2285.

184 [16] M. Masjedi-Arani, N. Mir, E. Noori, T. Gholami, M. Salavati-Niasari, Superlattice. Microst. 62 (2013) $185 \quad 30-38$.

186 [17] J. Tauc, R. Grigorovici, A. Vancu, J. Phys. Status. Solidi B. 15 (1966) 627-637.

187 [18] M. Hidalgo, M. Aguilar, M. Maicu, J. Navio, G. Colon, J. Catal. Today. 129 (2007) 50-58.

188 [19] F. Hossain, L. Sheppard, J. Nowotny, G. Murch, J. Phys. Chem. Solids. 69 (2008) 1820-1828.

189 


\section{Figure Captions:}

191 Fig. 1. XRD patterns of synthesized samples at different pH (a) 6, (b) 8 and (c) 10.

192 Fig. 2. SEM images of $\mathrm{Cd}_{2} \mathrm{~V}_{2} \mathrm{O}_{7}$ nanostructures prepared by different amines (a) $\mathrm{NH}_{3}$, (b) en, (c) TETA, (d) 193 TEPA and (e) TEM image of optimum sample (sample No.3).

194 Fig. 3. SEM images of cadmium vanadate nanostructures prepared in different conditions (a-d) sample No. 195 6-9, (e) sample No. 1 and (f) sample No. 10.

196 Fig. 4. SEM images of cadmium vanadate nanostructures prepared by different solvents (a) Methanol, (b) 197 PG, (c) Butanol and (d) Isobutanol.

$198 \quad$ Fig. 5. (a) FT-IR spectrum and (b) EDS spectrum of sample No. 3.

199 Fig. 6. (a, b) UV-Vis diffuse absorption spectra and (c, d) plot of $(\alpha h v)^{2}$ versus (hv) of sample No.3 and 1 , 200 respectively.

201 Fig. 7. Photocatalytic eosin Y degradation of cadmium vanadate nanoparticles under visible light (a) sample 202 No. 1 and (b) sample No. 3.

203 Scheme. 1. Schematic diagram of formation of cadmium vanadate nanostructures by different basic and 204 capping agent. 


\begin{tabular}{|c|c|c|c|c|c|}
\hline Sample no & Basic factor & Reaction time (h) & Reaction temperature $\left({ }^{\circ} \mathrm{C}\right)$ & $\mathbf{p H}$ & Solvent \\
\hline 1 & - & 2 & R.T & 6 & $\mathrm{H}_{2} \mathrm{O}$ \\
\hline 2 & $\mathrm{NH}_{3}$ & 2 & R.T & 8 & $\mathrm{H}_{2} \mathrm{O}$ \\
\hline 3 & en & 2 & R.T & 8 & $\mathrm{H}_{2} \mathrm{O}$ \\
\hline 4 & TETA & 2 & R.T & 8 & $\mathrm{H}_{2} \mathrm{O}$ \\
\hline 5 & TEPA & 2 & R.T & 8 & $\mathrm{H}_{2} \mathrm{O}$ \\
\hline 6 & en & $20 \mathrm{~min}$ & R.T & 8 & $\mathrm{H}_{2} \mathrm{O}$ \\
\hline 7 & en & 24 & R.T & 8 & $\mathrm{H}_{2} \mathrm{O}$ \\
\hline 8 & en & 2 & 3 & 8 & $\mathrm{H}_{2} \mathrm{O}$ \\
\hline 9 & en & 2 & 80 & 8 & $\mathrm{H}_{2} \mathrm{O}$ \\
\hline 10 & en & 2 & R.T & 10 & $\mathrm{H}_{2} \mathrm{O}$ \\
\hline 11 & en & 2 & R.T & 8 & Methanol \\
\hline 12 & en & 2 & R.T & 8 & PG \\
\hline 13 & en & 2 & R.T & 8 & Butanol \\
\hline 14 & en & 2 & R.T & 8 & Isobutanol \\
\hline
\end{tabular}

207 Table 1. Reaction conditions for cadmium vanadate nanostructures.

208

209 


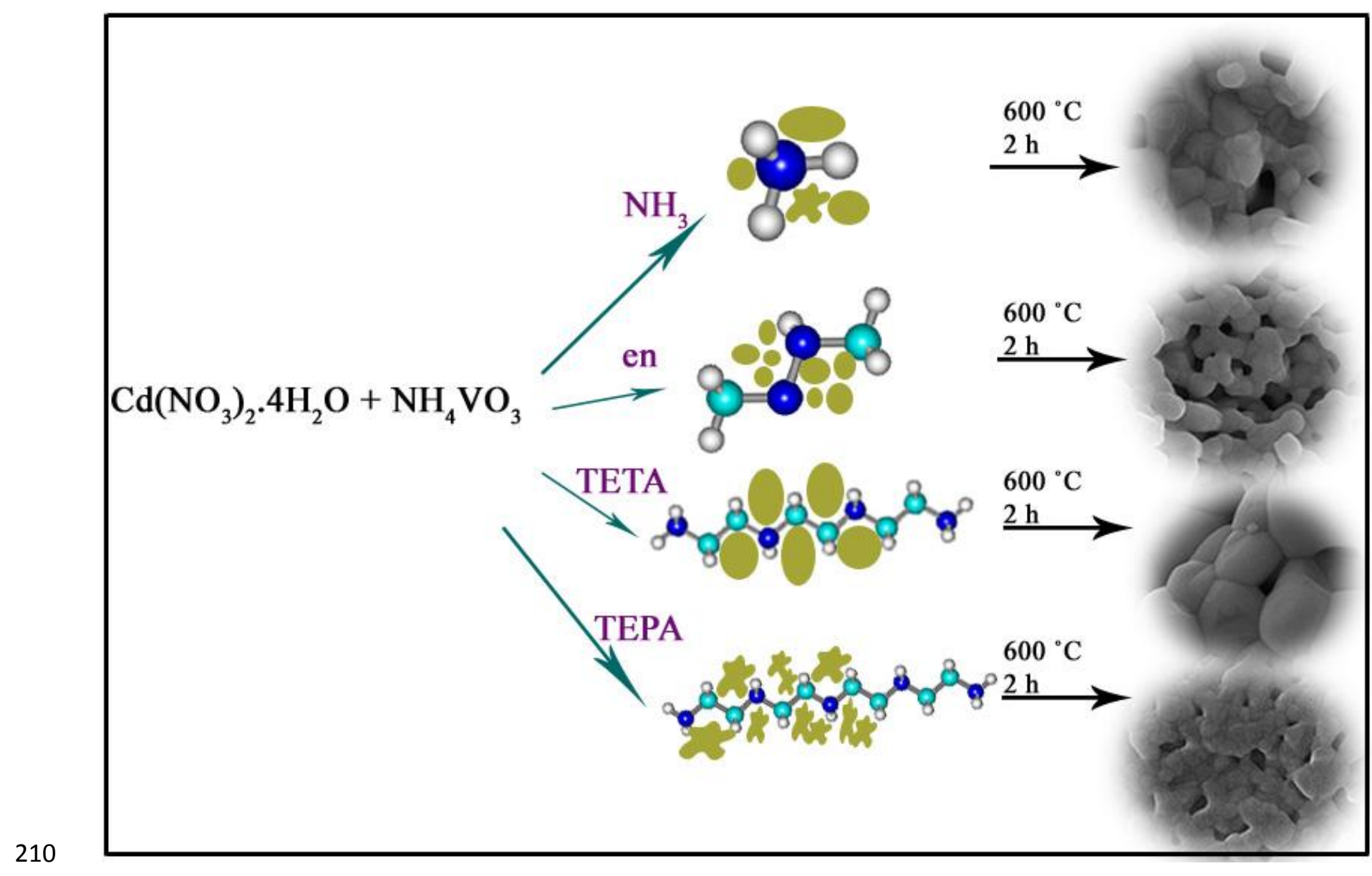

211 Scheme. 1.

212 


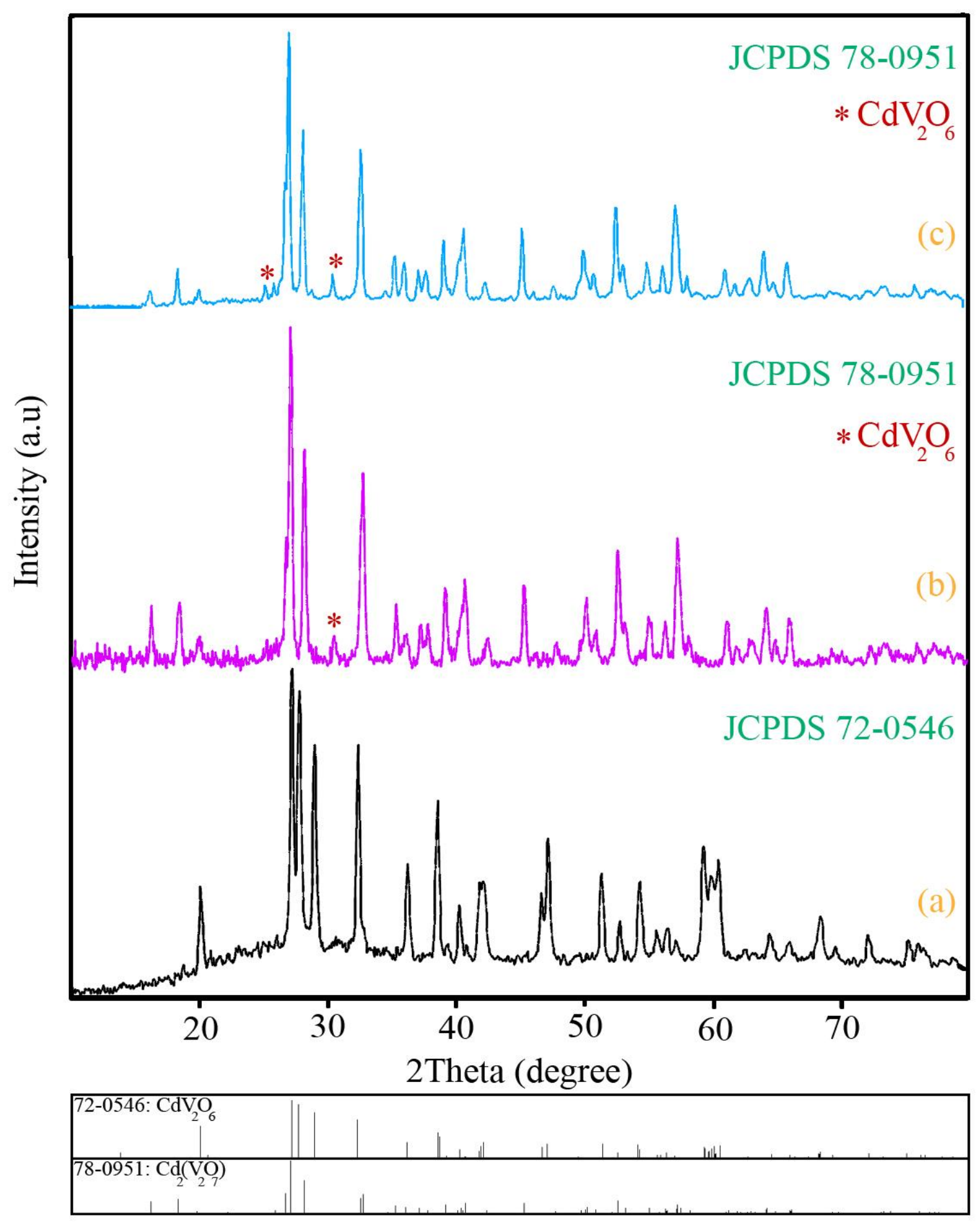

Fig. 1. 

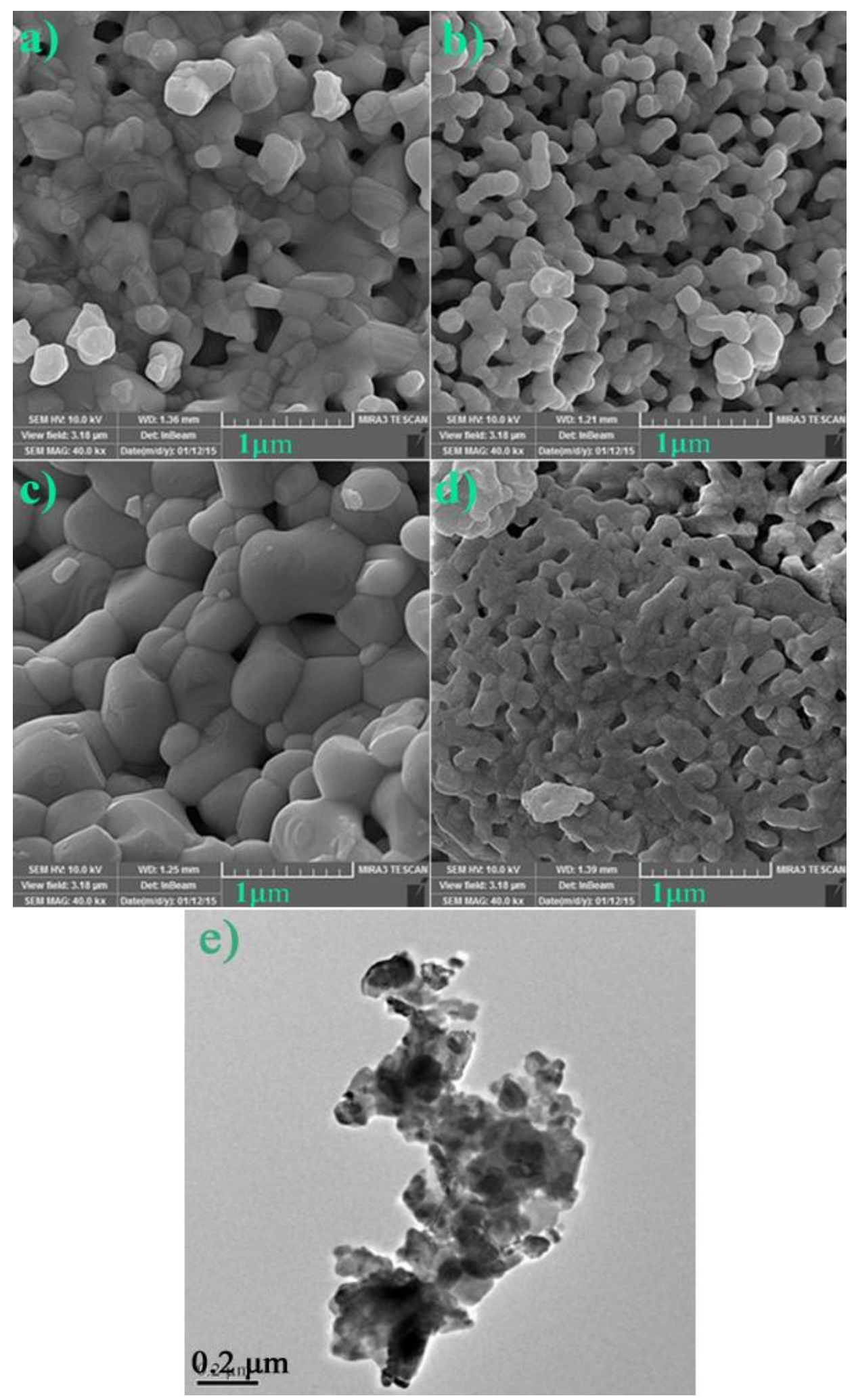

$217 \quad$ Fig. 2. 


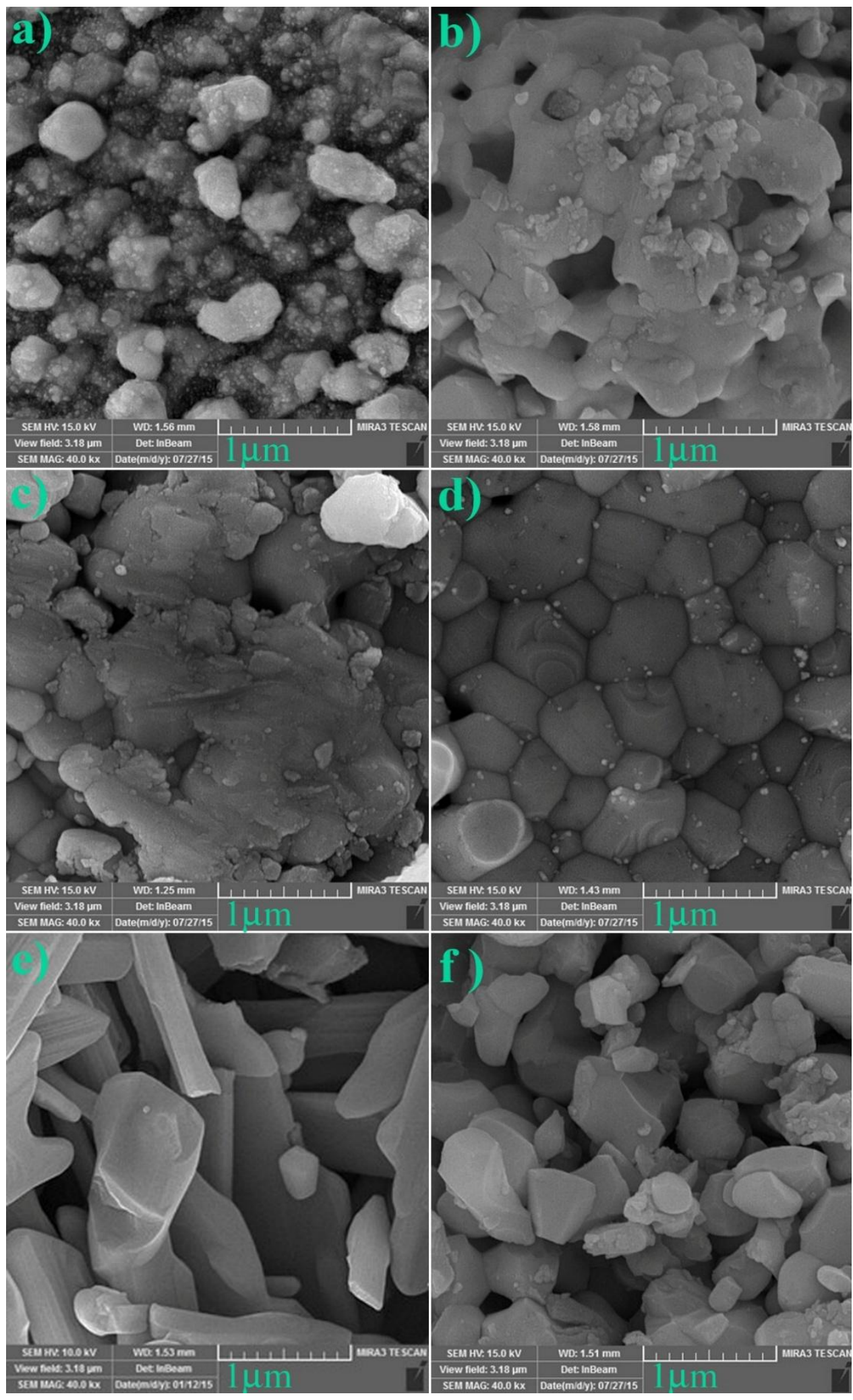

220 Fig. 3. 


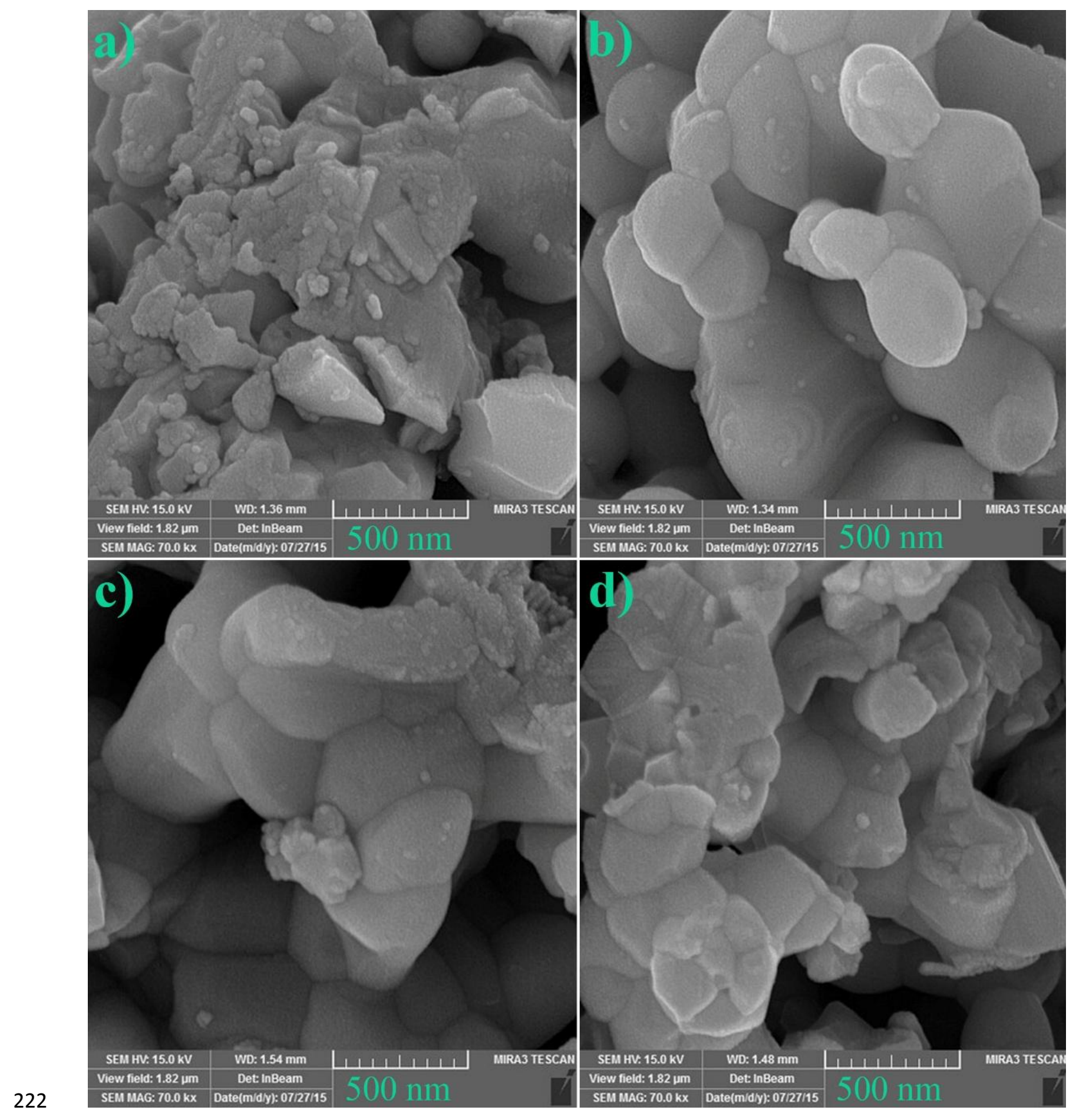

223 Fig. 4. 

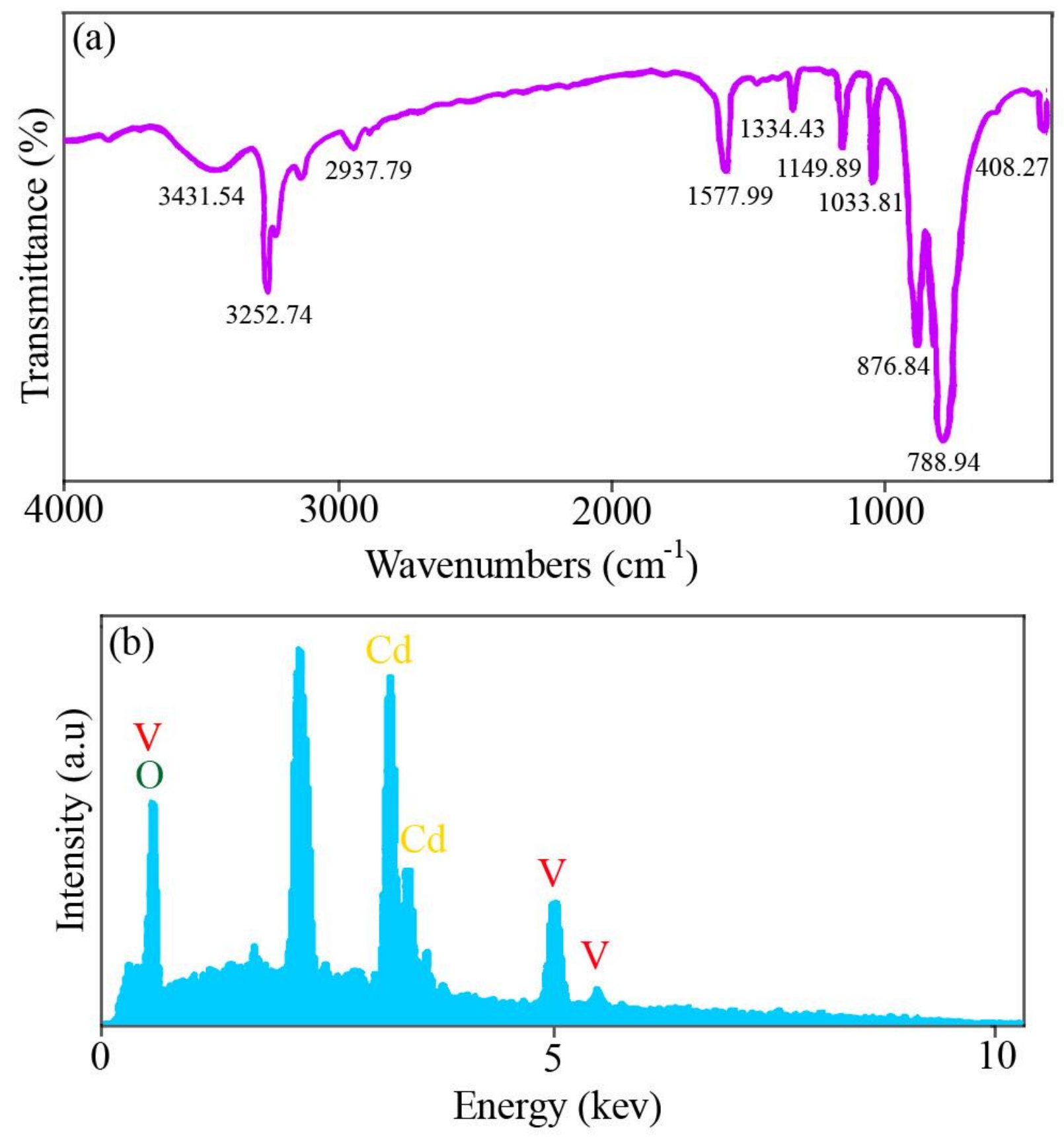

$226 \quad$ Fig. 5.

227 


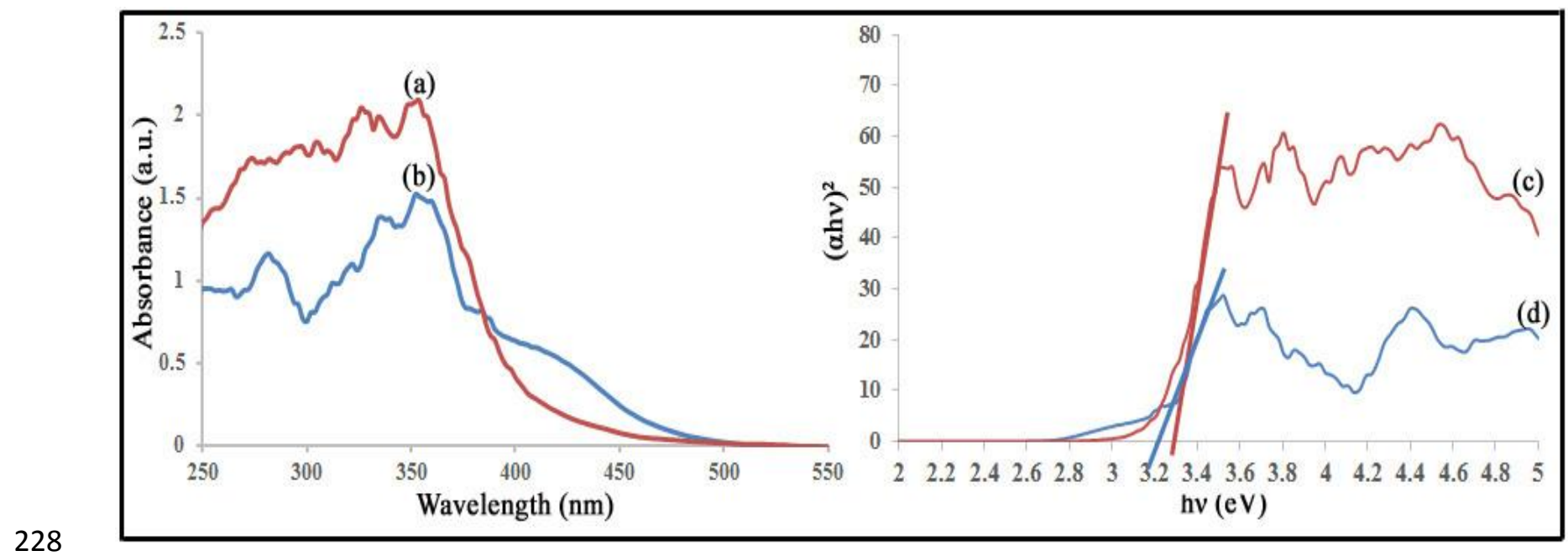

229 Fig. 6.

230 


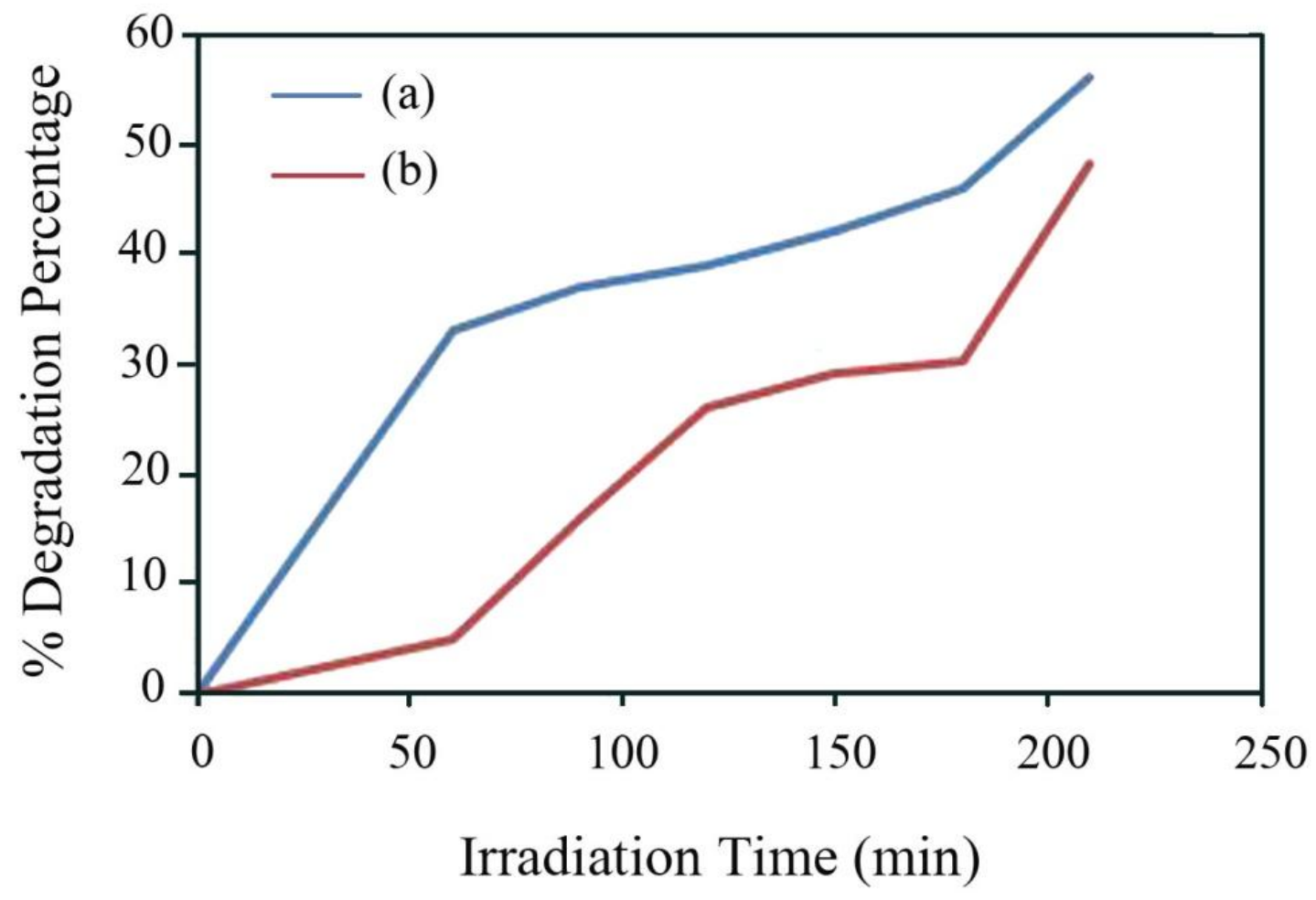

232 Fig. 7.

233 


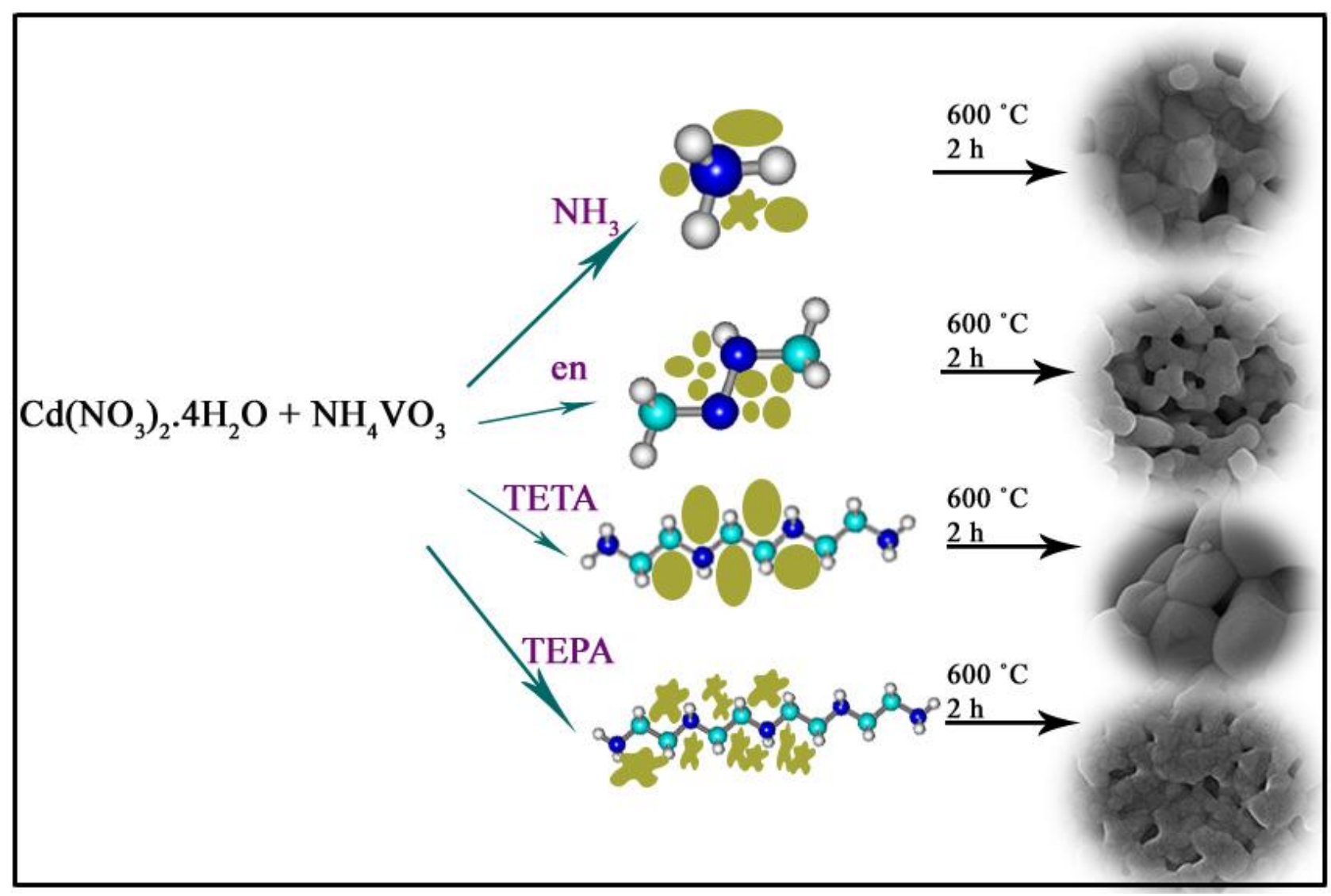

